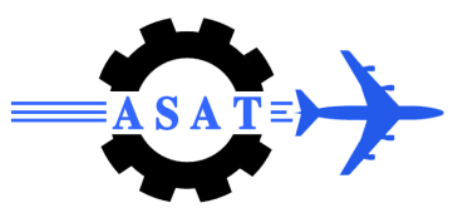

\title{
Improving Vehicle Ride Response using a Shock Absorber with Dual Damping Characteristics
}

\author{
M.A. Ajaj ${ }^{*}$, A.M. Sharaf ${ }^{\dagger}$, S.A. Hegazy ${ }^{\ddagger}$ and Y.H. Hossamel-deen ${ }^{\S}$
}

\begin{abstract}
This paper presents a detailed investigation of vehicle ride response using a semiactive suspension with a shock absorber of dual damping characteristics. For the purpose of vehicle ride analysis, different mathematical models have been developed with different levels of complexity. Numerical simulation has been carried out through the MATLAB/Simulink environment and aids the future development of controllable suspension systems to improve the vehicle's ride comfort. A detailed parametric study has been introduced to investigate the effect of suspension system parameters on the ride comfort. The findings conform to natural intuition and well known published research.
\end{abstract}

Keywords: vehicle suspension, ride comfort, dual damping characteristics, switchable damper.

\section{Nomenclature}

$\mathrm{a}, l_{f}$

$\mathrm{b}, l_{r}$

$\mathrm{C}$

$c_{f}, c_{r}$

$c_{t f}, c_{t r}$

$c_{s}, c_{t}$

$k_{s}, k_{t}$

$k_{f}, k_{r}$

$k_{t f}, k_{t r}$

$M_{b}$

$m_{w}$

$m_{w f}, m_{w r}$

$z_{s}, z_{w}$

$\dot{z}_{s}, \dot{z}_{w}$

$\ddot{z}_{S}, \ddot{z}_{w}$

$z_{r}$ distance from the front axle to the center of gravity, (m).

distance from the rear axle to the center of gravity, (m).

distance from right, lift wheel to the center of gravity, (m).

damping coefficients of front and rear suspension, (N.s/m).

damping coefficients of front and rear tires, (N.s/m).

damping coefficient of shock absorber and tire; respectively, (N.s/m).

stiffness of suspension and tire; respectively, $(\mathrm{N} / \mathrm{m})$.

stiffness of front and rear springs, $(\mathrm{N} / \mathrm{m})$.

stiffness of the front and rear tires, $(\mathrm{N} / \mathrm{m})$.

sprung mass, $(\mathrm{kg})$.

unsprung mass, $(\mathrm{kg})$.

front and rear unsprung mass, $(\mathrm{kg})$.

displacements of the sprung and unsprung masses; respectively, (m).

velocities of sprung and unsprung masses; respectively, $(\mathrm{m} / \mathrm{s})$. accelerations of sprung and unsprung masses; respectively, $\left(\mathrm{m} / \mathrm{s}^{2}\right)$. road input displacement, $(\mathrm{m})$.

\footnotetext{
Egyptian Armed Forces, Egypt, ajaj.mustafa@yahoo.com

${ }^{\dagger}$ Egyptian Armed Forces, Egypt, al_hossein2005@hotmail.com

\$Egyptian Armed Forces, Egypt, shawky26@yahoo.com

${ }^{\S}$ Professor, Chairman of Dept of Mechanical and Mechatronics Eng, HTI, yehia.hendawy@hti.edu.eg
} 


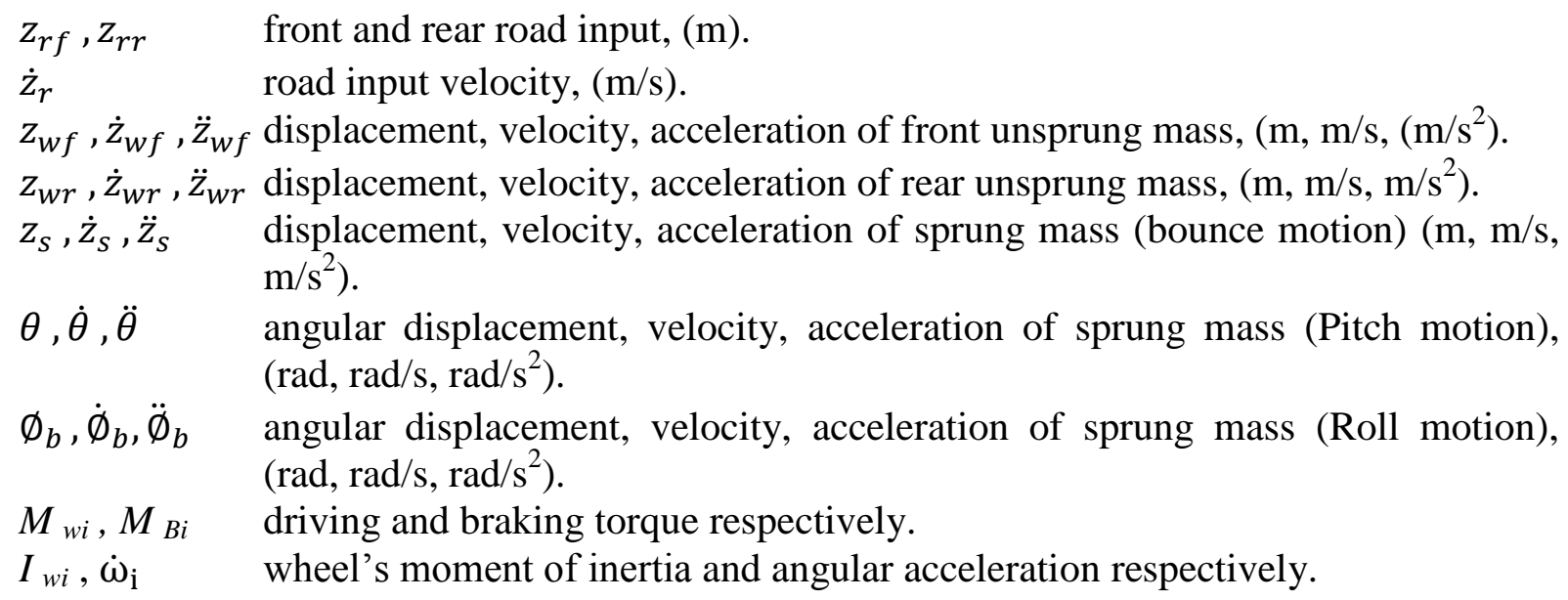

\section{Introduction}

The adverse conflict between ride and tire-road holding ability of vehicles fitted with a conventional passive suspension system has been reported as a challenging problem [1]. The tire-road holding ability in terms of vehicle stability and performance is improved using rigid suspension with higher damping coefficient. On contrary, better ride response in terms of lower vertical acceleration is achieved using softer suspension with lower damping coefficient [2].

Over the years a considerable amount of work has been carried out resulting in a wide range of controllable suspension systems varying in cost, sophistication and effectiveness [3]. Among these systems semi-active suspensions with dual damping characteristics are receiving considerable attention due to its lower cost, lower weight, lower power consumption and competitive performance compared with other types [4].

For passive suspension system, the shock absorber has to quickly dampen the vehicle body motion and keep dynamic wheel force change small. Dual damping characteristics shock absorber varies its damping force according to a predetermined control algorithm. It has two operating modes with fixed force-velocity characteristics. The first mode is characterized by high damping force and the second mode characterized by low damping force. Such dampers use an electromagnetic valve capable of switching the damper between its operating modes at frequencies sufficient to control wheel vibrations as well as body motions in real time [5].

This paper presents a detailed investigation for the possibility of improving the vehicle response to road unevenness using semi-active suspension with dual damping characteristics. Different levels of mathematical models with different complexity are introduced to simulate the vehicle ride characteristics. For the purpose of realistic investigation, the characteristics of the shock absorber and springs are obtained experimentally and incorporated in the simulation through look-up tables. The spring stiffness is obtained using a developed tailored simple test experiment to get the load deflection curve. The damping characteristics of a shock absorber with dual damping characteristics are obtained using a more advanced computerized test rig. 


\section{Mathematical Modeling}

\subsection{The Quarter Car Model (2-DOF)}

Vehicle suspension system is modeled as a single quarter of the four corners of the vehicle, this 2-DOF system is often referred to as the 'Quarter-Car Model' as shown in Fig. 1. The quarter car model consists of an unsprung or wheel mass $\left(m_{w}\right)$, which is connected to approximately a quarter of the vehicle's sprung mass $\left(M_{b}\right)$ by a spring and a damper system. The two-degrees-of-freedom model includes the vertical displacement of the vehicle quarter body sprung mass $\left(z_{s}\right)$ and the vertical displacement of the wheel centre $\left(z_{w}\right)$. It is assumed that all forces are vertically directed. The equations of motion for the quarter car model are derived by applying Newton's second law of motion as follows:

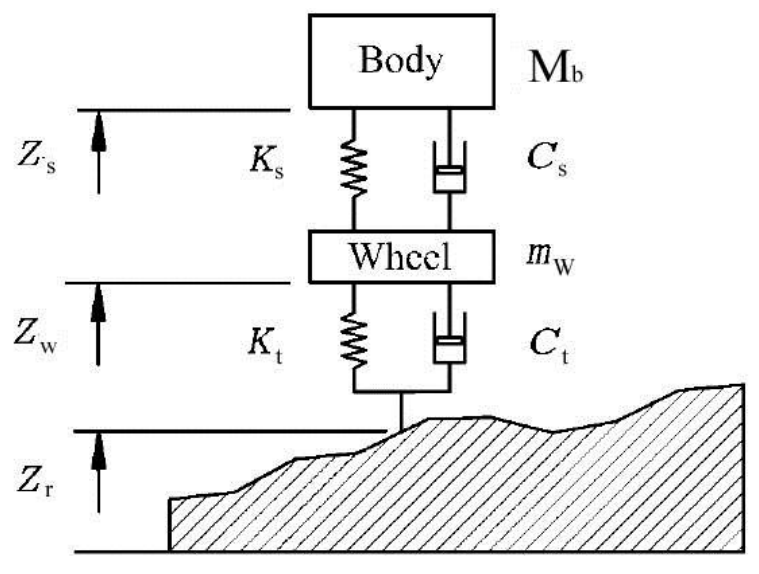

Fig. 1 The quarter car model

$$
\begin{gathered}
M_{b} \ddot{z}_{s}+c_{s}\left(\dot{z}_{s}-\dot{z}_{w}\right)+k_{s}\left(z_{s}-z_{w}\right)=0 \\
m_{w} \ddot{z}_{w}-c_{s}\left(\dot{z}_{s}-\dot{z}_{w}\right)-k_{s}\left(z_{s}-z_{w}\right)+c_{t}\left(\dot{z}_{w}-\dot{z}_{r}\right)+k_{t}\left(z_{w}-z_{r}\right)=0
\end{gathered}
$$

\subsection{The Half Car Model (4-DOF)}

It is composed of a sprung mass $\left(M_{b}\right)$ representing the vehicle body together with two unsprung masses $\left(m_{u f}, m_{u r}\right)$ which represent the front and rear axles. The sprung mass is linked to the unsprung masses through spring and shock absorber as shown in Fig. 2. Two vibration modes are considered for sprung mass namely heave $\left(Z_{s}\right)$ and $\operatorname{pitch}(\theta)$ while for unsprung masses only heave motion $\left(Z_{w f}, Z_{w r}\right)$ is considered. The suspension springs are represented by an equivalent front and rear linear spring $\left(k_{f}, k_{r}\right)$ and the damping elements are represented by an equivalent front and rear shock absorber $\left(C_{f}, C_{r}\right)$. The front and rear tires are considered by linear springs stiffness $\left(k_{t f}, k_{t r}\right)$ and damping coefficient $\left(C_{t f}, C_{t r}\right)$. The governing equations of motion can be obtained by considering the forces and moments as follows: 


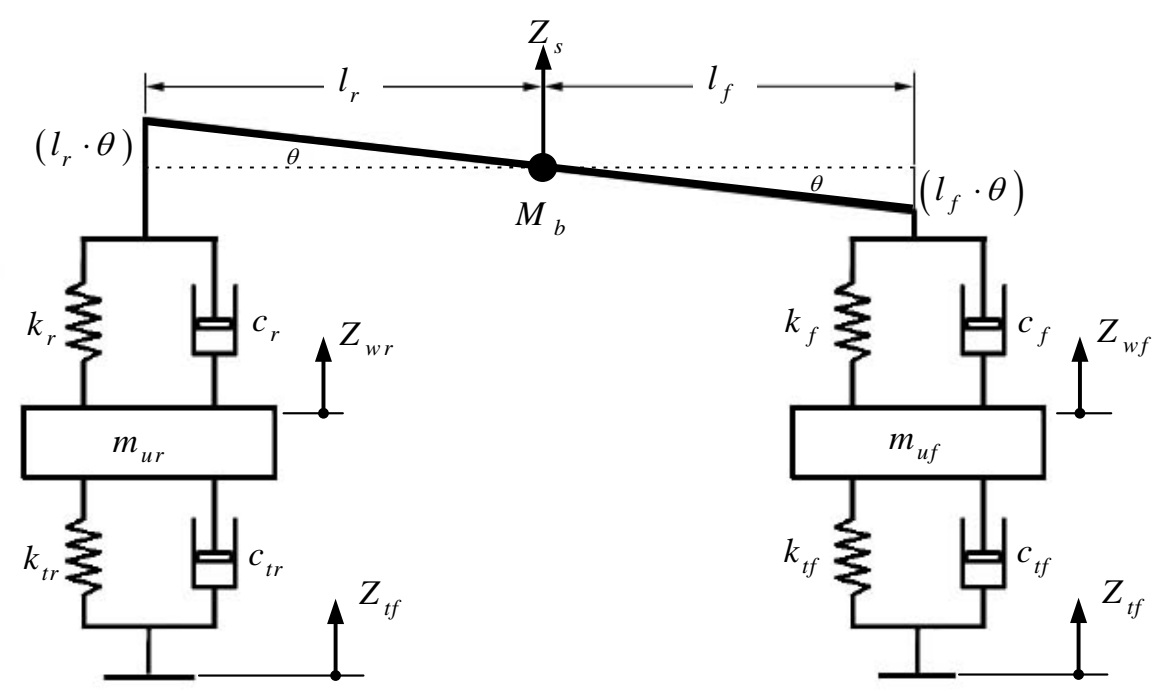

Fig. 2 The half car model (4-DOF)

$$
\begin{gathered}
M_{b} \ddot{z}_{s}+c_{f}\left[\dot{z}_{s}+l_{f} \dot{\theta}-\dot{z}_{w f}\right]+c_{r}\left[\dot{z}_{s}-l_{r} \dot{\theta}-\dot{z}_{w r}\right]+k_{f}\left[z_{s}+l_{f} \theta-z_{w f}\right] \\
\quad+k_{r}\left[z_{s}-l_{r} \theta-z_{w r}\right]=0 \\
I_{p} \ddot{\theta}+c_{f}\left[\dot{z}_{s}+l_{f} \dot{\theta}-\dot{z}_{w f}\right] l_{f}-c_{r}\left[\dot{z}_{s}-l_{r} \dot{\theta}-\dot{z}_{w r}\right] l_{r}+k_{f}\left[z_{s}+l_{f} \theta-z_{w f}\right] l_{f} \\
\quad-k_{r}\left[z_{s}-l_{r} \theta-z_{w r}\right] l_{r}=0 \\
m_{u f} \ddot{z}_{w f}-c_{f}\left[\dot{z}_{s}+l_{f} \dot{\theta}-\dot{z}_{w f}\right]-k_{f}\left[z_{s}+l_{f} \theta-z_{w f}\right]+k_{t f}\left[z_{w f}-z_{r f}\right] \\
\quad+c_{t f}\left[\dot{z}_{w f}-\dot{z}_{r f}\right]=0 \\
m_{u r} \ddot{z}_{w r}-c_{r}\left[\dot{z}_{s}-l_{r} \dot{\theta}-\dot{z}_{w r}\right]-k_{r}\left[z_{s}-l_{r} \theta-z_{w r}\right]+k_{t r}\left[z_{w r}-z_{r r}\right]+c_{t r}\left[\dot{z}_{w r}-\dot{z}_{r r}\right] \\
=0
\end{gathered}
$$

\subsection{The Full Vehicle Ride Model (7-DOF)}

The full-vehicle suspension model shown in Fig. 3 consists of sprung mass $\left(M_{b}\right)$ with three degrees of freedom namely; bounce $\left(z_{s}\right)$ roll $(\phi)$ and pitch $(\theta)$ motions. Another four masses are added to represent the unsprung masses $\left(M_{i}\right)$. For simplicity all tires are replaced with equal stiffness $\left(k_{t}\right)$ and tire damping coefficient $\left(C_{t}\right)$. The suspension, tire are modeled by linear springs $\left(k_{s}\right)$ in parallel with shock absorber. Using the Newton's second law of motion, the following equations of motion can be derived.

$$
\begin{gathered}
M_{b} \ddot{z}_{s}+c_{1}\left(\dot{z}_{5}-\dot{z}_{1}\right)+c_{2}\left(\dot{z}_{6}-\dot{z}_{2}\right)+c_{3}\left(\dot{z}_{7}-\dot{z}_{3}\right)+c_{4}\left(\dot{z}_{8}-\dot{z}_{4}\right) \\
\quad+k_{1}\left(z_{5}-z_{1}\right) \ldots \ldots+k_{2}\left(z_{6}-z_{2}\right)+k_{3}\left(z_{7}-z_{3}\right)+k_{4}\left(z_{8}-z_{4}\right)=0 \\
I_{b} \ddot{\theta}_{b}+c_{1}\left(\dot{z}_{5}-\dot{z}_{1}\right) a+c_{2}\left(\dot{z}_{6}-\dot{z}_{2}\right) b+c_{3}\left(\dot{z}_{7}-\dot{z}_{3}\right) b+c_{4}\left(\dot{z}_{8}-\dot{z}_{4}\right) a+k_{1}\left(z_{5}-z_{1}\right) a \ldots \\
\ldots+k_{2}\left(z_{6}-z_{2}\right) b+k_{3}\left(z_{7}-z_{3}\right) b+k_{4}\left(z_{8}-z_{4}\right) a=0 \\
I_{b} \ddot{\emptyset}_{b}+c_{1}\left(\dot{z}_{5}-\dot{z}_{1}\right) c+c_{2}\left(\dot{z}_{6}-\dot{z}_{2}\right) c+c_{3}\left(\dot{z}_{7}-\dot{z}_{3}\right) c+c_{4}\left(\dot{z}_{8}-\dot{z}_{4}\right) c+k_{1}\left(z_{5}-z_{1}\right) c \ldots \\
\ldots+k_{2}\left(z_{6}-z_{2}\right) c+k_{3}\left(z_{7}-z_{3}\right) c+k_{4}\left(z_{8}-z_{4}\right) c=0 \\
m_{1} \ddot{z}_{1}-c_{1}\left(\dot{z}_{5}-\dot{z}_{1}\right)-k_{1}\left(z_{5}-z_{1}\right)+c_{t}\left(\dot{z}_{1}-\dot{q}_{1}\right)+k_{t}\left(z_{1}-q_{1}\right)=0 \\
m_{2} \ddot{z}_{2}-c_{2}\left(\dot{z}_{6}-\dot{z}_{2}\right)-k_{2}\left(z_{6}-z_{2}\right)+c_{t}\left(\dot{z}_{2}-\dot{q}_{2}\right)+k_{t}\left(z_{2}-q_{2}\right)=0 \\
m_{3} \ddot{z}_{3}-c_{3}\left(\dot{z}_{7}-\dot{z}_{3}\right)-k_{3}\left(z_{7}-z_{3}\right)+c_{t}\left(\dot{z}_{3}-\dot{q}_{3}\right)+k_{t}\left(z_{3}-q_{3}\right)=0
\end{gathered}
$$




$$
\begin{gathered}
m_{4} \ddot{z}_{4}-c_{4}\left(\dot{z}_{8}-\dot{z}_{4}\right)-k_{4}\left(z_{8}-z_{4}\right)+c_{t}\left(\dot{z}_{4}-\dot{q}_{4}\right)+k_{t}\left(z_{4}-q_{4}\right)=0 \\
z_{5}=z_{b}+c * \emptyset-a * \theta \\
z_{6}=z_{b}+c * \emptyset+b * \theta \\
z_{7}=z_{b}-c * \emptyset+b * \theta \\
z_{8}=z_{b}-c * \emptyset-a * \theta
\end{gathered}
$$

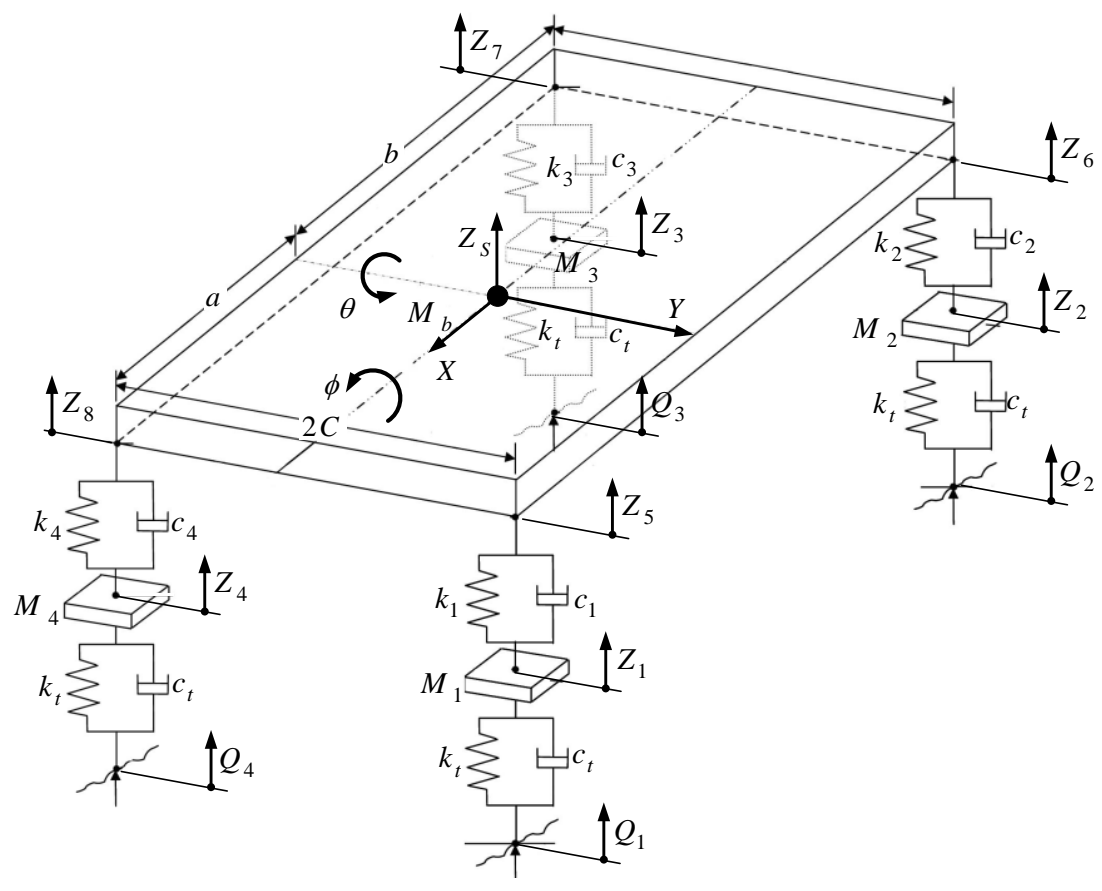

Fig. 3 The full vehicle ride model (7-DOF)

\section{4 The Full Vehicle Model (12-DOF)}

The vehicle body is assumed to be rigid, with mass $\left(m_{s}\right)$ and moments of inertia as shown in Fig. 4. The rigid body has six degrees of freedom, which includes three translations namely; forward velocity $(U)$ in $x_{\mathbf{L}}$-direction, lateral velocity $(V)$ in $y_{\mathbf{L}}$-direction and vertical velocity $(W)$ in $z_{\mathbf{L}}$-direction, in addition to three rotations namely; roll rate $(p)$ about $x_{\mathbf{L}}$ axis, pitch rate $(q)$ about $y_{\mathbf{L}}$ - axis and yaw rate $(r)$ about $z_{\mathbf{L}}$ - axis. The wheels are connected to the vehicle body via springs and shock absorbers. It is assumed that each wheel has two degrees of freedom, one for the vertical displacement $\left(z_{w_{i}}\right)$, and the other for wheel rotational driving speed $\left(\omega_{i}\right)$, the equations of motion for the lumped mass can be derived as follow [6]: 


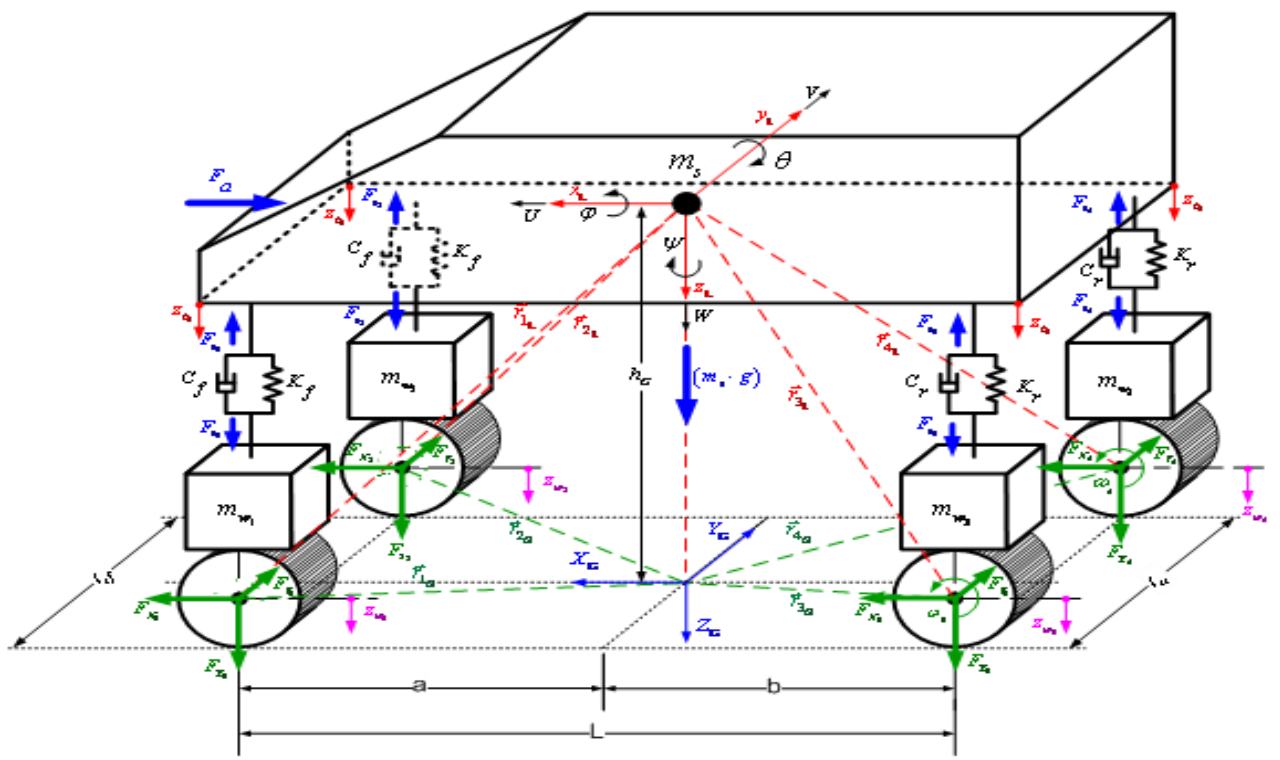

Fig. 4. The full vehicle model (12-DOF), [6]

$$
\begin{gathered}
\sum F_{x}=m_{s} \cdot(\dot{U}-V \cdot r+W \cdot q) \\
\sum F_{y}=m_{s} \cdot(\dot{V}-W \cdot p+U \cdot r) \\
\sum F_{z}=m_{s} \cdot(\dot{W}-U \cdot q+V \cdot p) \\
\sum M_{x}=I_{x x} \cdot \dot{p}-\left(I_{y y}-I_{z z}\right) \cdot q \cdot r-I_{z x} \cdot(p \cdot q+\dot{r}) \\
\sum M_{y}=I_{y y} \cdot \dot{q}-\left(I_{z z}-I_{x x}\right) \cdot r \cdot p-I_{x z} \cdot\left(p^{2}+r^{2}\right) \\
\sum M_{z}=I_{z z} \cdot \dot{r}-\left(I_{x x}-I_{y y}\right) \cdot p \cdot q+I_{z x} \cdot(r \cdot q+\dot{p}) \\
m_{i} \ddot{z}_{w i}=m_{w i} \cdot g+c_{i}\left(\dot{z}_{b i}-\dot{z}_{w i}\right)+k_{i}\left(z_{b i}-z_{w i}\right)+F_{z i}, w h e r e i=1: 4 \\
I_{w i} \cdot \dot{\omega}_{i}=M_{w i}-M_{B i}-M_{U i}, \text { where } i=1: 2
\end{gathered}
$$

\section{Experimental Measurements}

To evaluate the potential application of dual damping shock absorber in vibration control of vehicle suspension system, typical experimental measurements of the suspension system are carried out. The main purpose of these testing are to obtain the dynamic data necessary for identifying its model parameters such as spring stiffness and the typical characteristics of the shock absorber.

\subsection{Spring Stiffness Characteristics}

For the purpose of spring stiffness measurement, a special hydraulic test rig is employed. As shown in Fig. 5, the stiffness of the tested spring is obtained from the relation between the applied force and the displacement of the spring as shown in Fig. 6. 


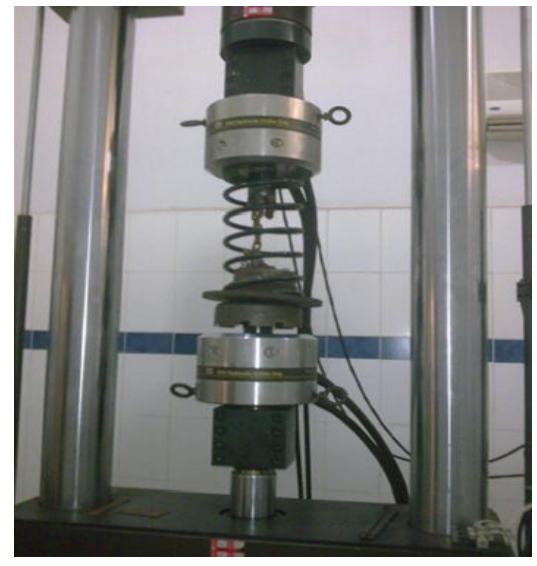

Fig. 5. Stiffness measurement

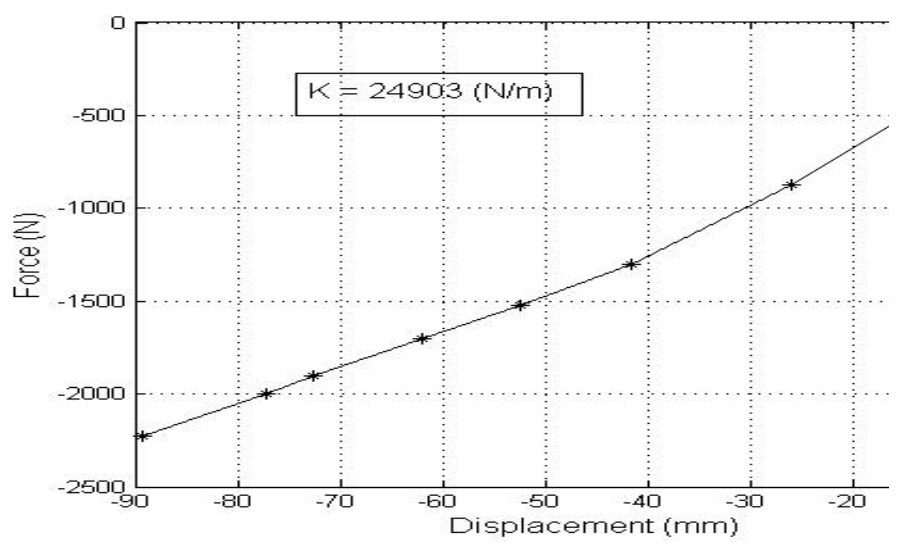

Fig. 6. Measurement results for spring stiffness

\subsection{Shock Absorber Damping Characteristics}

The MTS850 Shock Absorber Test System is used to measure the dual characteristics of the shock absorber [7], as shown in Fig. 7. The test machine has an upper and lower head with grippers that can hold the dampers in place. The lower head is attached to the hydraulic cylinder that can move up and down. The upper head incorporates a load cell to enable measuring the force applied to the damper. Excitation frequencies of 1, 2, 3 and $4 \mathrm{~Hz}$ can be applied while the displacement amplitudes of 80 and $120 \mathrm{~mm}$ are measured respectively as shown in Fig. 8-9. The applied current of the electro-hydraulic solenoid of the shock absorber is set to be zero for hard mode, and $0.5 \mathrm{~A}$ for soft mode. The applied force can be measured and registered through data acquisition connected to PC. The damping coefficient of the tested shock absorber is obtained from the relation between the applied force and the measured velocity of the damper.
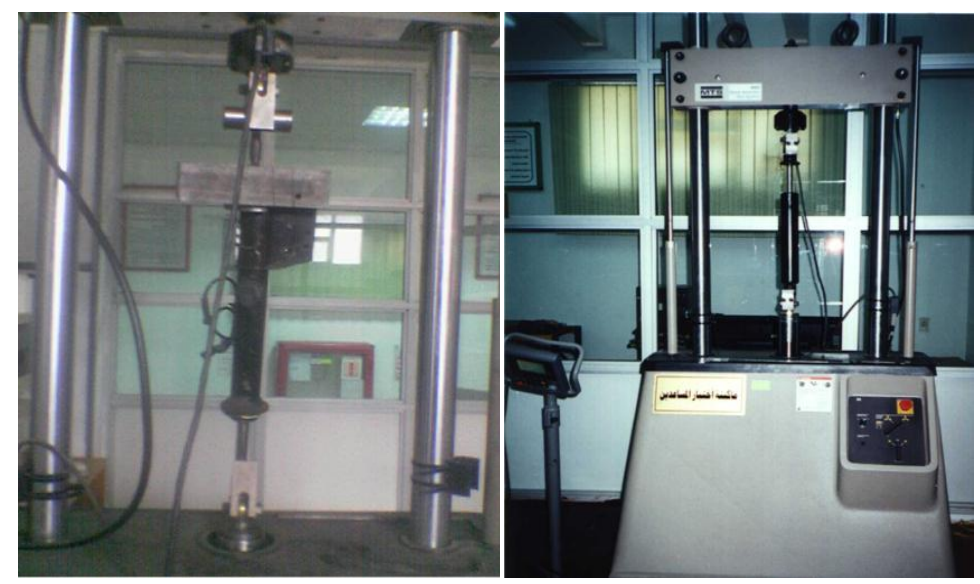

Fig. 7 The MTS850 shock absorber test system

It is obvious that as the excitation frequency increases, the applied force increases during both the compression and rebound strokes. This may be referred to the stored elastic energy in the shock absorber due to excitation [8]. Also by increasing the excitation frequency, the piston velocity of shock absorber is also increases at the compression and rebound strokes which increase the absorbed power and it may be calculated from the bounded area under by curves. The measured characteristics of the shock absorbers during soft and hard modes are incorporated in the numerical models in the form of look-up tables which enables the investigation of its characteristics on the ride response as shown in section 4 . 


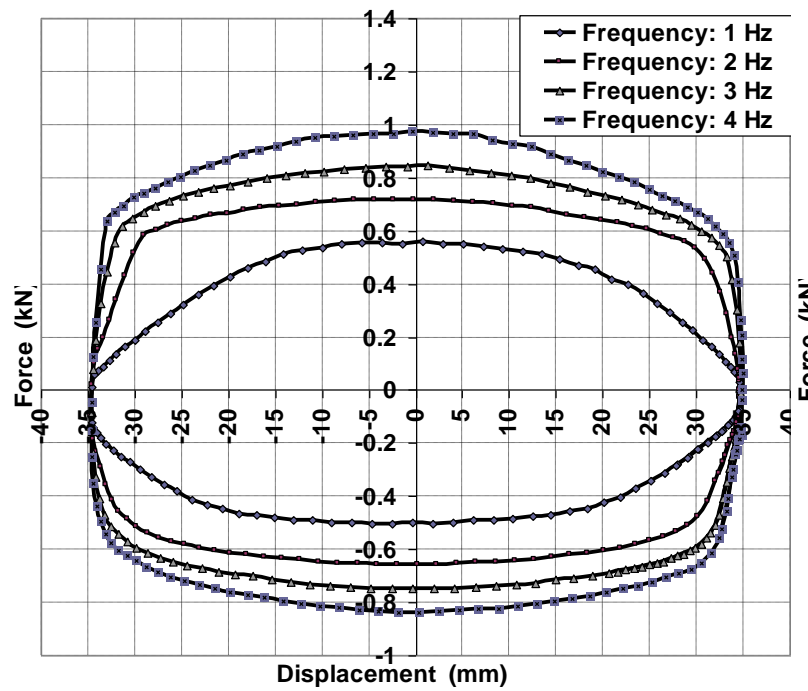

(a) Soft mode

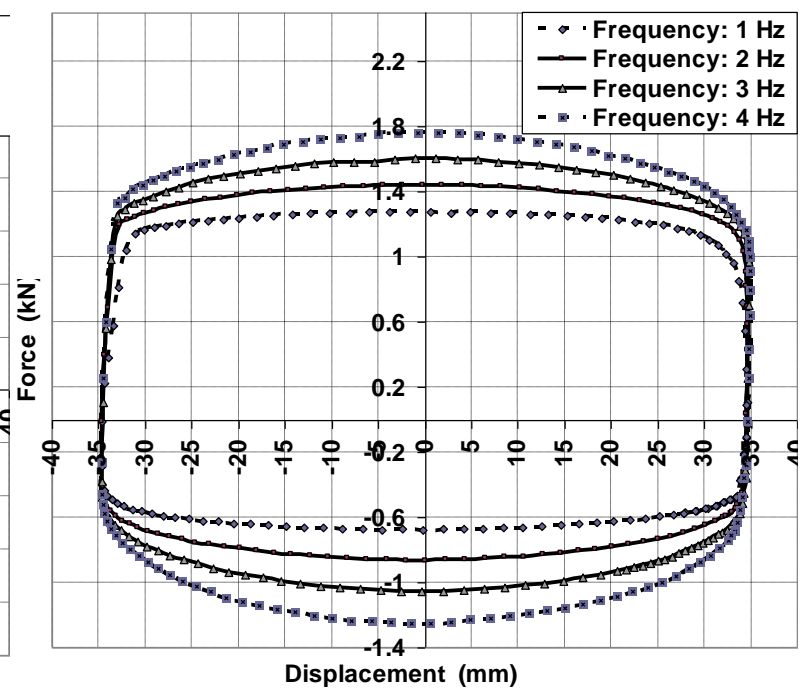

(b) Hard mode

Fig. 8 Measured damping force - displacement characteristics

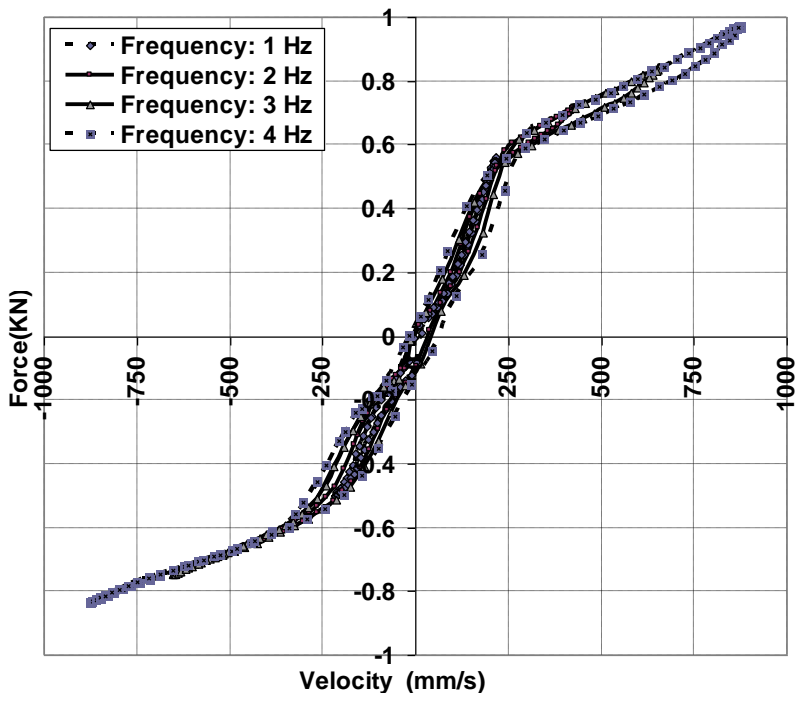

(a) Soft mode

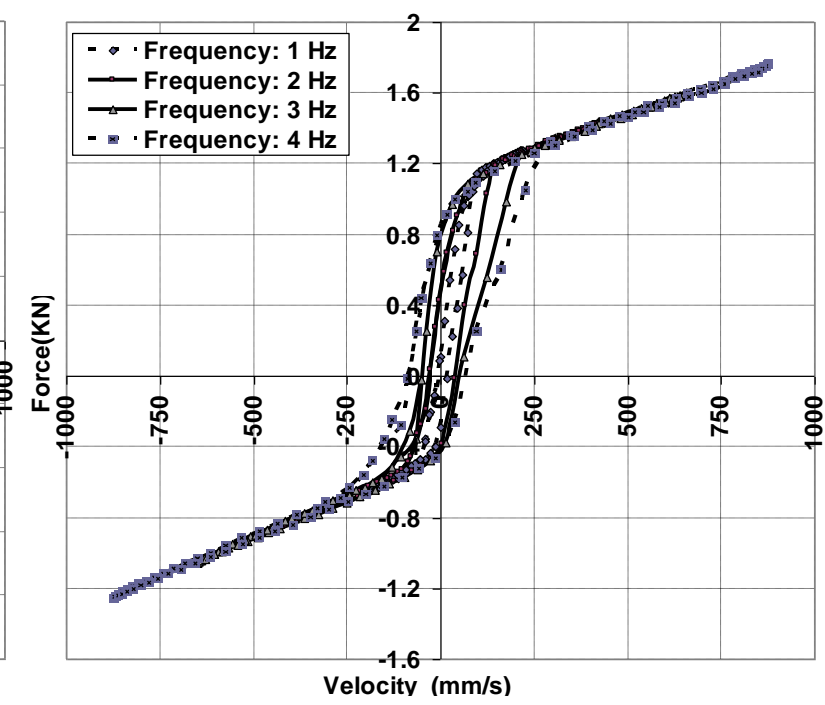

(b) Hard mode

Fig. 9 Measured damping force - velocity characteristics

\section{Results and Analysis}

Numerical simulations of the derived models in section 2 have been implemented in the MATLAB/SIMULINK environment. Road input excitation is simulated by sine wave with constant amplitude and wavelength. The vehicle forward velocity is linearly increased, such that the excitation frequency rises up and the vehicle ride response can be depicted [9]. For the purpose of models verification, the results are compared to the well known publications. For example, the illustrated results in Fig. 15 show an acceptable agreement to those published in [10]. Another agreement is obtained by comparison of the results of quarter car, half car and full vehicle models (7-DOF and 12 DOF) as shown in Fig. 12, 13 and 14. 


\subsection{Parametric Study Of Passive Suspension System}

\subsubsection{Sprung mass}

Referring to Fig. 10-a, it can be noted that below the sprung mass natural frequency, lower values of sprung mass reduces body vertical acceleration. With further increase of the excitation frequency, the body acceleration is increased for lower mass. It is obvious that the body resonating frequency varies with sprung mass according to the relation: $\omega_{n}=\sqrt{k_{s} / M_{b}}$

\subsubsection{Unsprung mass}

The effect of unsprung mass on ride response is shown in Fig. 10-b. Close to the natural frequency of the sprung mass, the effect of unsprung mass on ride is minute. This effect increases gradually with the increase of excitation frequency particularly at the natural frequency of the unsprung mass (around $10 \mathrm{~Hz}$ ). The lighter the unsprung mass, the lower the sprung acceleration will be. However, for frequency range above the unsprung mass natural frequency, a lighter unsprung mass will lead to a slightly higher sprung acceleration; this is in agreement with ref. [10].

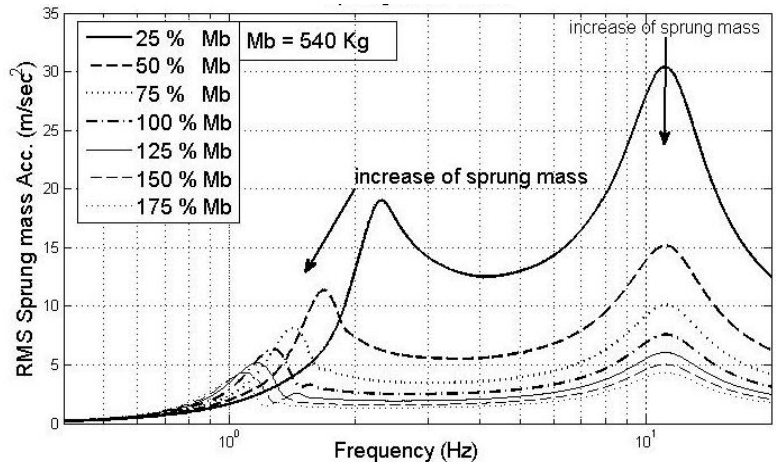

(a) Effect of sprung mass

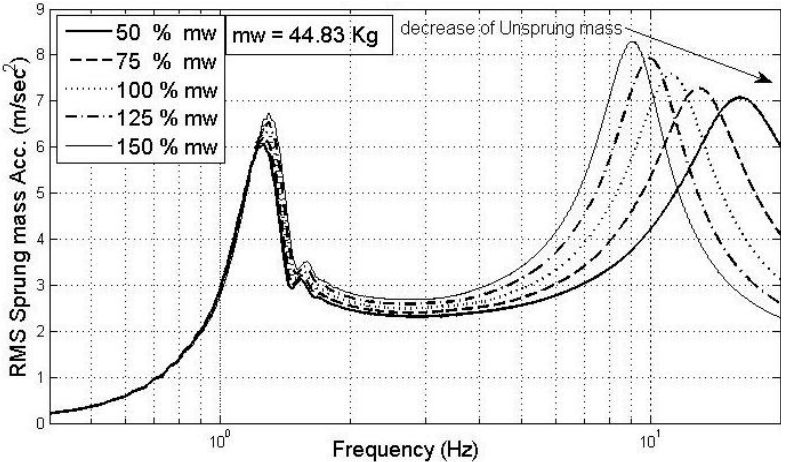

(b) Effect of unsprung mass

Fig. 10 Frequency response of a quarter-car model

\subsubsection{Suspension stiffness}

The suspension stiffness controls the ride behavior dramatically as shown in Fig. 11-a. stiffer suspension spring increases the transmission of road input to the vehicle body and therefore increases both the sprung mass acceleration and its resonating frequency value. In addition, the stiffer springs elevates the wheel hop mode near $10 \mathrm{~Hz}$, allowing more vibration transmission in the high frequency range. While this analysis shows the benefit of soft suspension for ride isolation, the practical limit is the suspension working space, [11].

\subsubsection{Shock absorber damping coefficient}

From Fig. 11-b, it can be noted that, close to the sprung mass natural frequency, the higher the damping ratio, the lower the sprung acceleration will be. For higher frequency range, the lower the damping ratio, the lower the sprung acceleration will be. At a frequency close to the natural frequency of the unsprung mass, there are two cases depending on the tire damping, in the case where neglecting the tire damping, the damping ratio has little effect on the response of the sprung mass, as well be shown latter, while when induced the tire damping, the lower the damping ratio, the lower the sprung acceleration will be, [10].

The result reflects the demand to control the damping coefficient, as the damping increases, the resonant peaks at sprung-mass natural frequency are attenuated, but the isolation is lost both at high frequency and at frequencies between the two natural frequencies of the system, sprung and unsprung natural frequencies. The lack of isolation between the two natural 
frequencies is caused by the increased coupling of the two degrees of freedom with a stiffer damper. The lack of isolation at higher frequencies will result in a harsher vehicle ride. The vehicle operators may find the harsh ride objectionable, or it may physically damage vehicle. Where as a lightly damped suspension will yield a more comfortable ride, but would significantly reduce the stability of the vehicle during turns. Therefore, a suspension design is an art of compromise between these two goals.

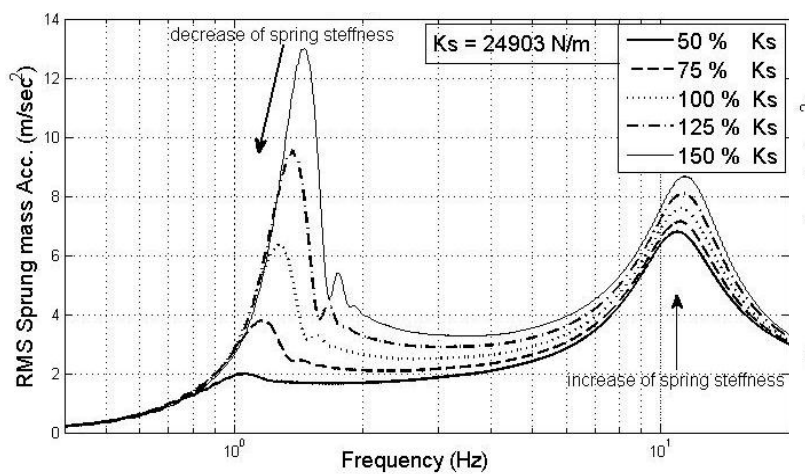

(a) Effect of spring stiffness

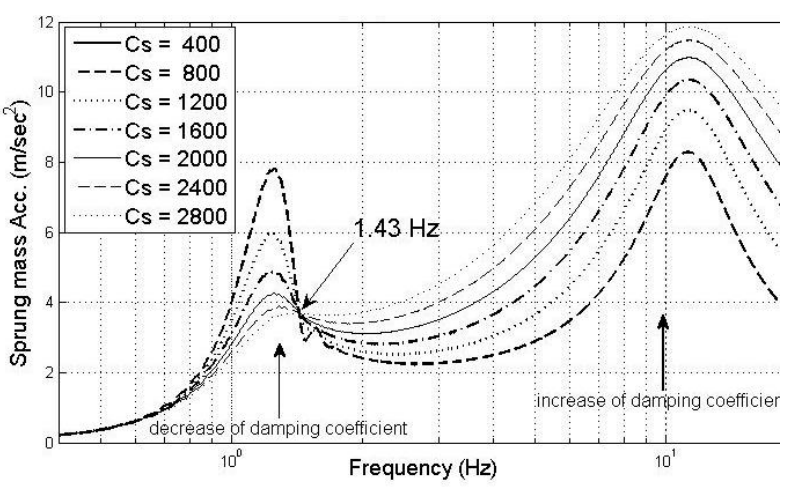

(b) Effect of damping coefficient

Fig. 11 Frequency response of a Q-Car model

\subsection{Ride Response Of Semi-Active suspension with Dual Damping Characteristics}

The results of different suspension models which are derived in section two are depicted and analyzed. Three type of excitation inputs are considered namely; tire/wheel force, vehicle body force and road roughness.

\subsubsection{Unsprung mass excitation}

Figure 12 illustrates the sprung mass response due to an excitation force at the axle and tire/wheel assembly. Usually, the transmissibility ratio (or transfer function) can be used as a basis for assessing the vibration isolation characteristics of a linear suspension system. It can be noted that, vehicles are more sensitivity to tire/wheel non-uniformities acting near the resonant frequency of the wheel such that the wheel force is transmitted directly to the sprung mass, [11]. At low frequency $(<1.46 \mathrm{~Hz})$ hard damping mode is recommended while at high frequencies soft damping mode is recommended. The results of all models $(2,4,7$ and 12 DOF) confirm the same behavior. As shown Fig. 12-a when the tire damping is ignored the responses at unsprung mass natural frequency are the same for hard and soft damping, [10$11]$.

\subsubsection{Sprung Mass Excitation:}

Figure 13 illustrates the sprung mass response due to an excitation force applied directly to the sprung mass. At high frequencies the gain approaches unity because the displacements become so small that suspension forces no longer change and the force is entirely dissipated as acceleration of the sprung mass, [11]. Also the figure shows that at low frequency $(<2.48)$ the hard damping mode gain is lower than that for soft mode especially at sprung resonance so hard damping mode is recommended while at high frequencies until unsprung mass resonance soft damping mode is recommended after that the gain in both hard and soft mode approaches unity. 


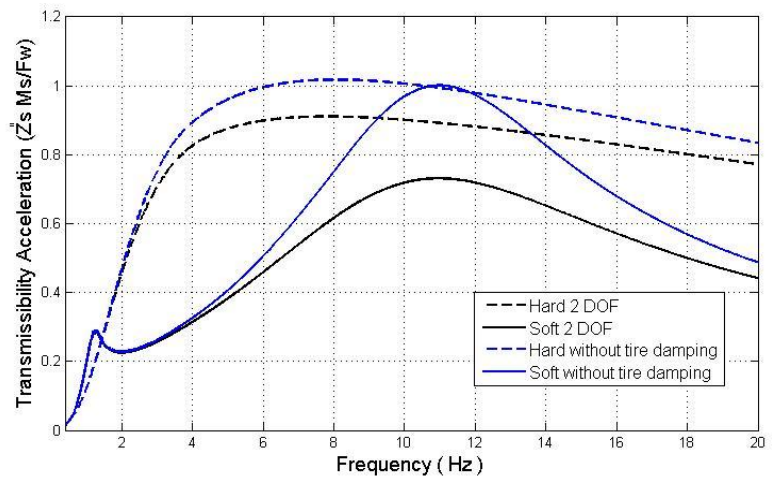

(a) The quarter car model (2-DOF)

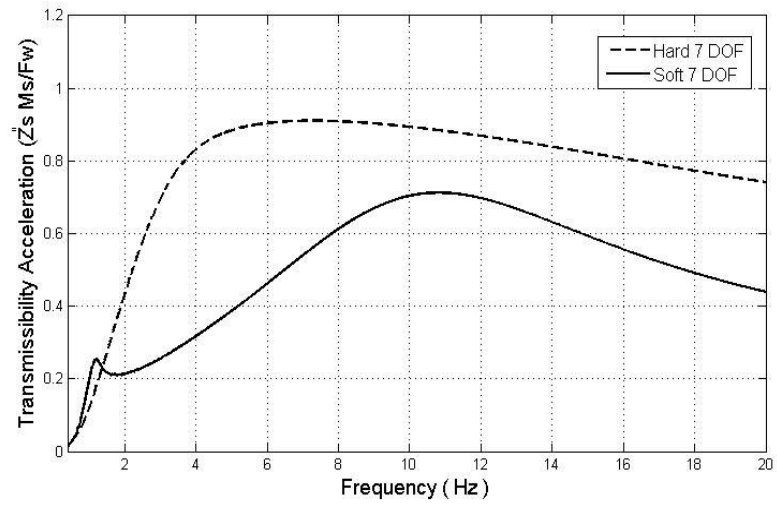

(c) The full vehicle ride model (7-DOF)

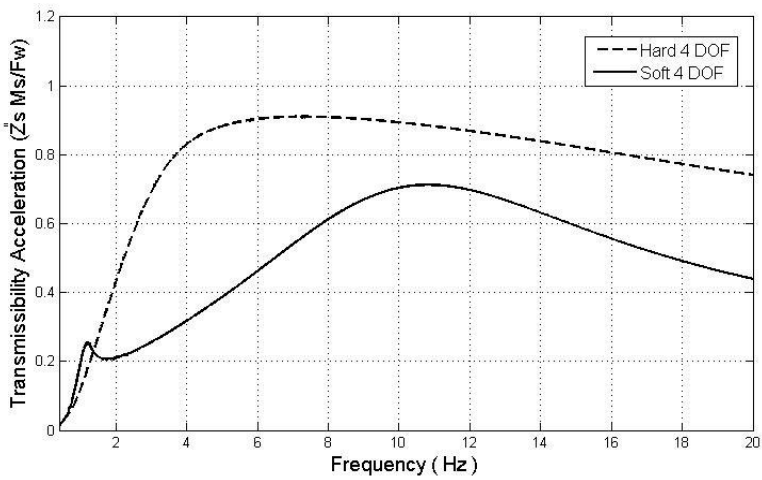

(b) The half car model (4-DOF)

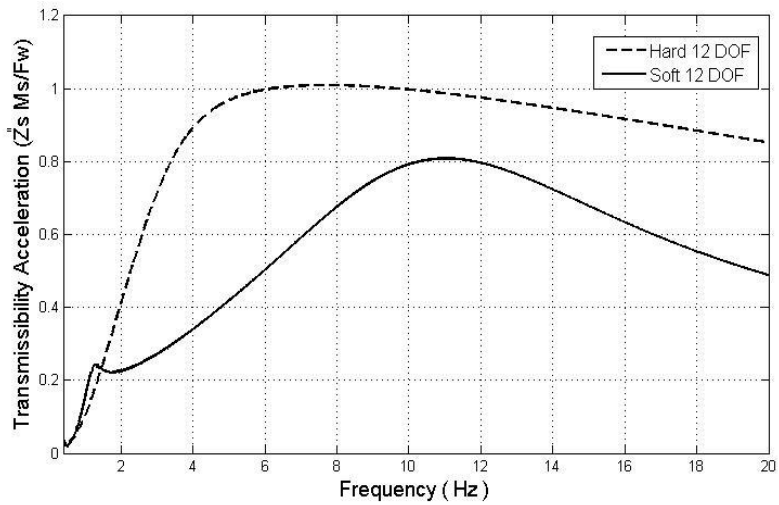

(d) The full vehicle model (12-DOF)

Fig. 12 Transmissibility response to tire/wheel force input

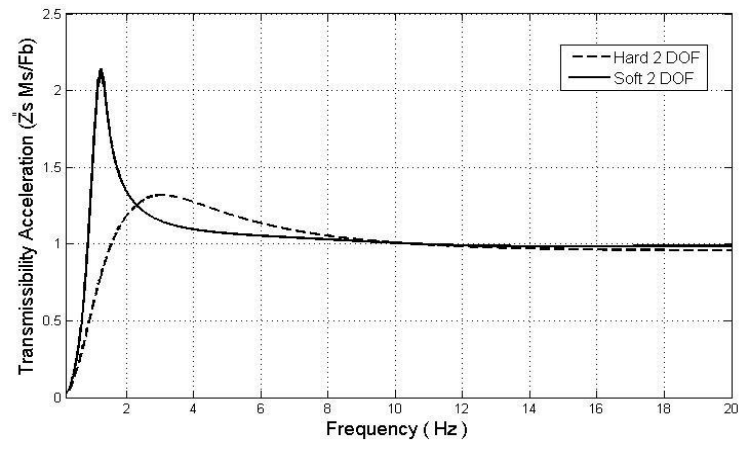

(a) The quarter car model (2-DOF)

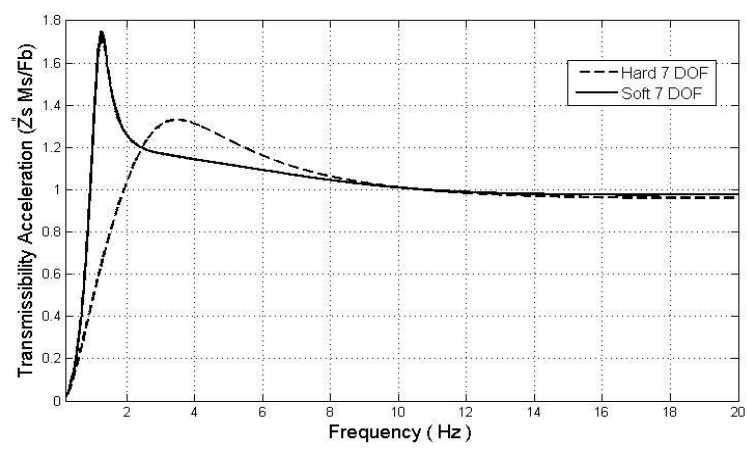

(c) The full vehicle ride model (7-DOF)

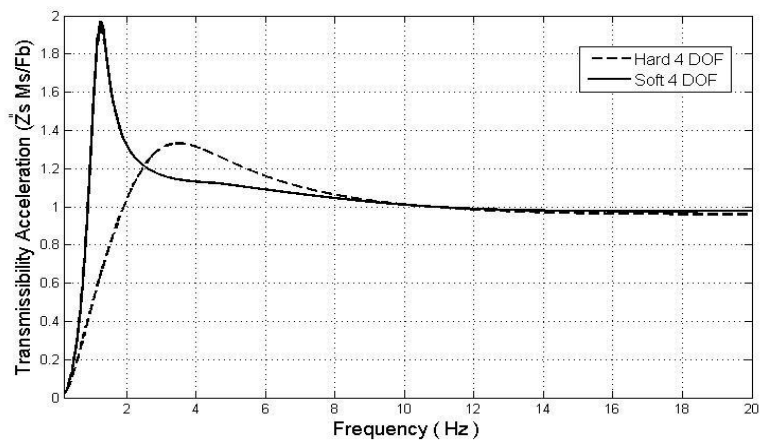

(b) The half car model (4-DOF)

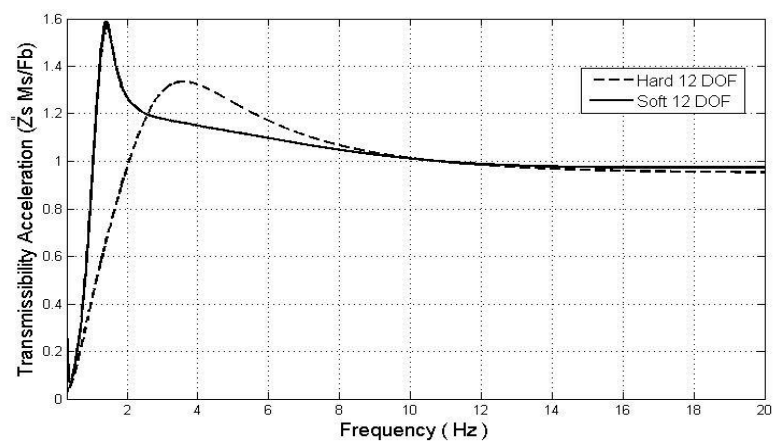

(d) The full vehicle model (12-DOF)

Fig. 13 Transmissibility response to body force input 


\subsubsection{Road excitation}

Figure 14 illustrates the sprung mass response due to an excitation input from the road. At very low frequency the gain is unity (the sprung mass moves in exact duplication of the road input). By classical design of motor vehicles, the sprung mass is chosen to have its natural frequency at or just above $1 \mathrm{~Hz}$. Therefore, at frequencies near $1 \mathrm{~Hz}$ the sprung mass is resonating on the suspension and the road inputs are amplified. The amplitude ratio at this peak is very sensitive to damping level, and on typical passenger cars will be in the range of 1.5 to 3 . Above resonance, the road inputs are increasingly attenuated. In the range of 10 to 12 $\mathrm{Hz}$, the unsprung mass of the tire/wheel assembly goes into a vertical (hop) resonance mode, adding a small bump to the attenuation curve in this region.

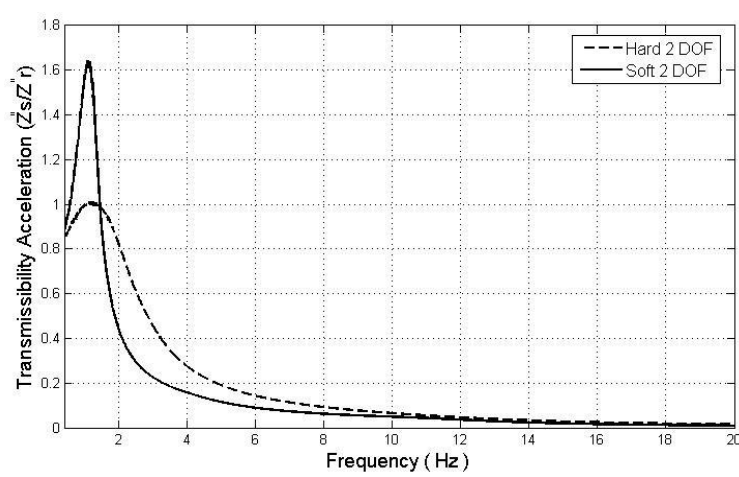

(a) The quarter car model (2-DOF)

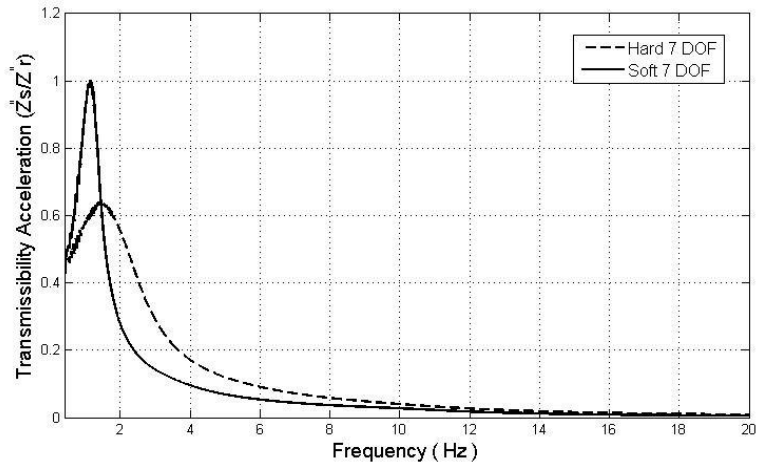

(c) The full vehicle ride model (7-DOF)

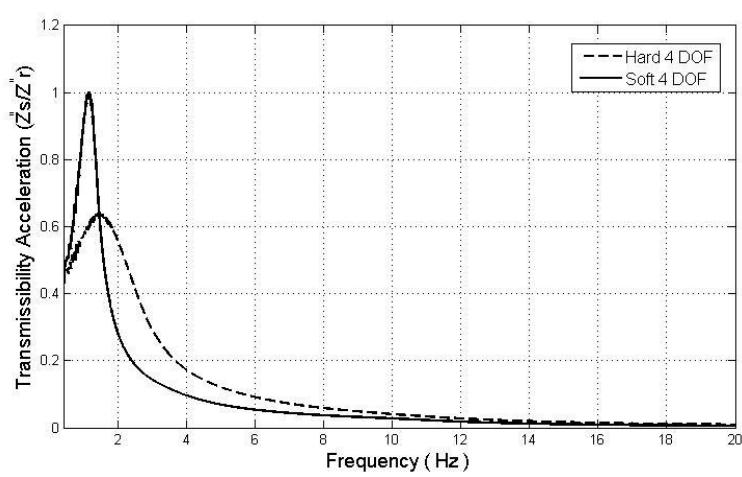

(b) The half car model (4-DOF)

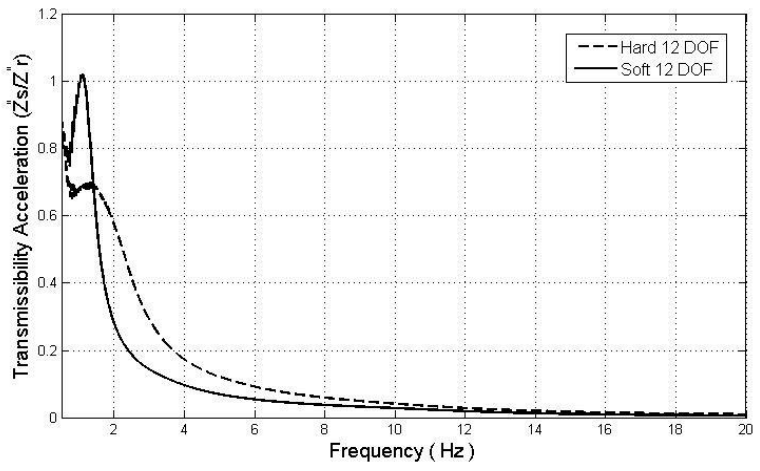

(d) The full vehicle model (12-DOF)

Fig. 14 Transmissibility Response to Road Roughness Input

\subsection{Optimum Suspension Damping}

Figure 15 illustrates the adverse conflict between ride and tire-road holding ability of vehicles fitted with a dual damping characteristics (soft and hard). This conflict can be noted in terms of sprung mass vertical acceleration, relative displacement between the sprung and unsprung mass and tire deflection. For each term the ride response is described by the transmissibility ratio and the vertical acceleration RMS. The input excitation is considered by linearly increasing the vehicle speed over a sinusoidal road with constant amplitude.

\subsubsection{Vibration Isolation}

It can be seen from Fig. 15-a that, in the frequency range close to the natural frequency of the sprung mass, hard damping value reduces the transmissibility ratio. In the frequency range between the natural frequency of the sprung mass and that of the unsprung mass, soft damping value is the best choice to reduce transmissibility, [12]. When he tire damping is 
neglected, the sprung mass acceleration increases especially close to the natural frequency of the unsprung mass, this effect is more sensitive when the suspension incorporates softer shock absorber.

\subsubsection{Suspension Travel}

It defines the space required to accommodate the suspension spring movement between bump and rebound stops, commonly known as the "rattle space". The suspension travel as a function of frequency is presented in Fig. 15-b. Two peaks can be pointed out, with soft damper setting, wheel travel in relation to vehicle body becomes significantly larger at both the natural frequencies of the body and the wheel, [12]. Also it can be seen that at low frequency, hard damper provide better response and at mediate and high frequencies, except at unsprung natural frequency. This indicates that to reduce the suspension travel, a hard damper is required.
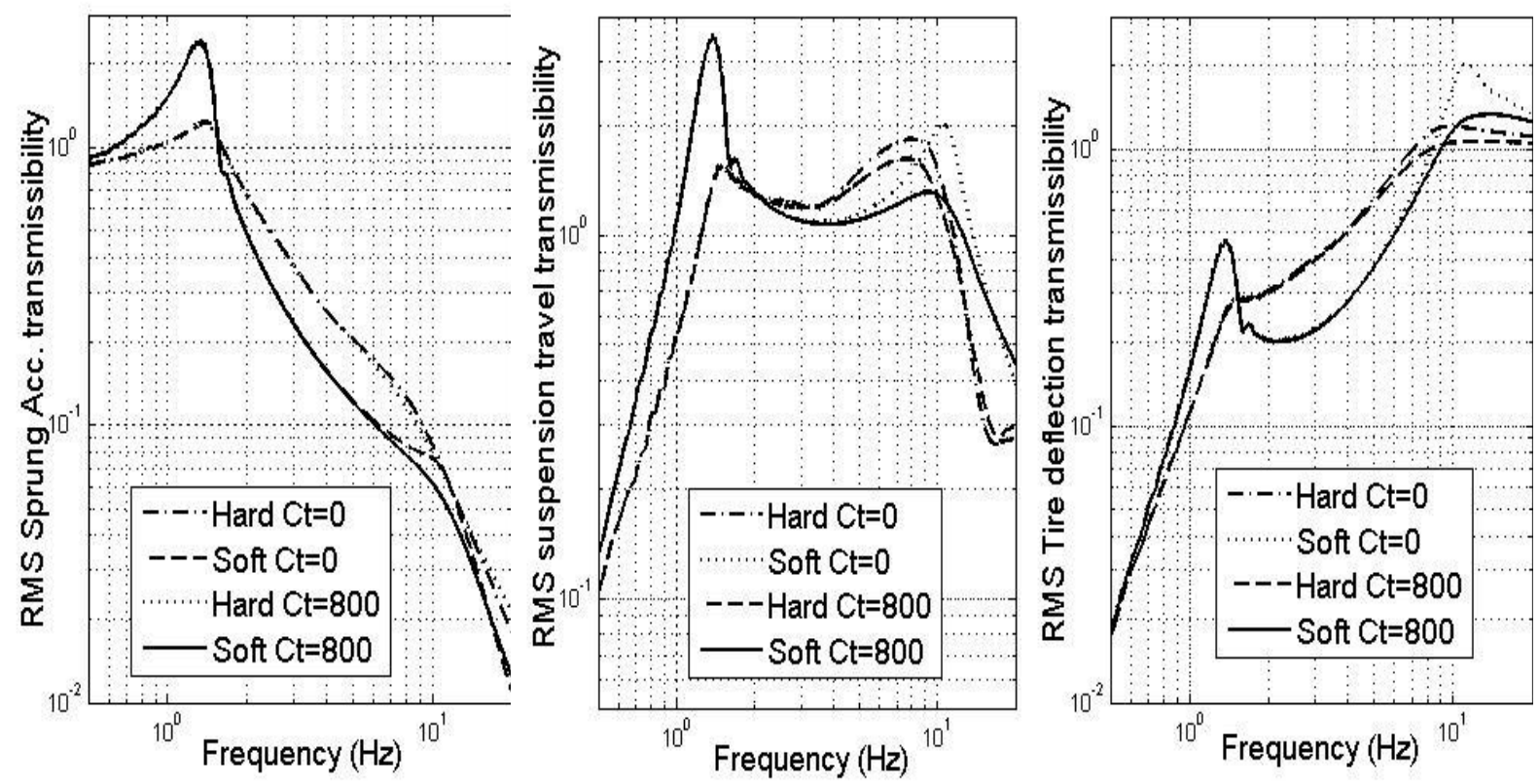

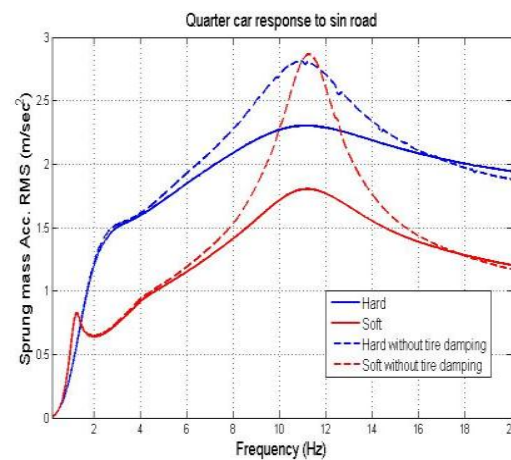

(a) Sprung mass

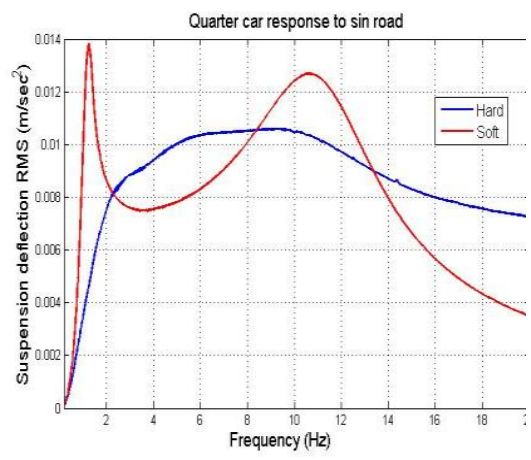

(b) Suspension travel

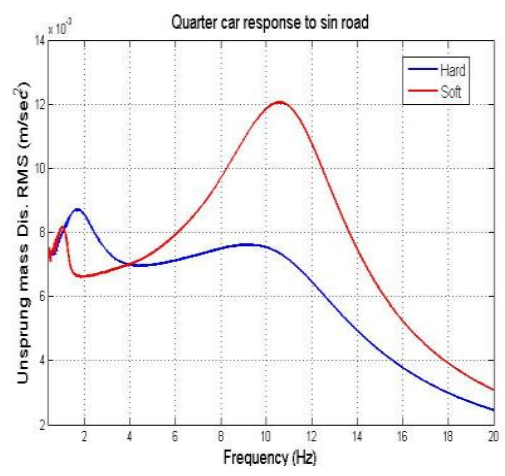

(C) Tire deflection

Fig. 15 Conflict of Ride and Handling Damping Effect

\subsubsection{Road-Holding}

When the vehicle system vibrates, the normal force acting between the tire and the road fluctuates. Since the cornering force, tractive effort, and braking effort developed by the tire are related to the normal load on the tire, the vibration of the tire affects the road-holding capability and influences the handling and performance of the vehicle. The normal force 
between the tire and the road during vibration can be represented by the dynamic tire deflection or by the displacement of the unsprung mass relative to the road surface, [10]. As shown in Fig. 15-c, at frequencies lower than sprung natural frequency hard damper provide low tire deflection. In mediate frequencies soft damper provide low tire deflection.

In general, four regions on the curves in Fig. 15, a, b, c can be analyzed as follow:

1. From zero frequency up to the natural frequency of the sprung mass: both comfort and road holding capabilities are improved with the hard damper, i.e. they are both superior compared to results achieved with a softer damper.

2. Regular ride between the resonance peaks of the system: In this region, both of the criteria are improved with a softer damping setting. The human body is most sensitive to the vibrations at this frequency range.

3. Wheel hop around the natural frequency of the wheel. Handling is improved in this region with a stiffer damper. The comfort suffers a minor penalty with the stiffer damping setting. Poor damping at this frequency range has a severe influence to the driving characteristics on rough roads.

4. Harshness above wheel hop frequency. In this region, a softer damper shows improved comfort, while a minor penalty in road holding is suffered.

\section{Conclusion}

A comprehensive computer simulation models with different level of complexity to investigate the ride response of motor vehicle has been introduced. Furthermore, the contribution of main design parameters of passive suspension system has been addressed. The adverse conflict between ride response and tire-road holding ability of vehicles fitted with a dual damping characteristics (soft and hard) has been investigated and the optimum damping has been recommended in order to optimize the vehicle performance. These results may contribute to propose a new control system of a dual damping shock absorber depending on the frequency of the output RMS of the sprung mass acceleration and relative displacement of the suspension. The introduced full vehicle models will aids to optimize the damping coefficient and proper switching time to maintain not only good ride comfort but also to keep the safe vehicle dynamics in both roll and pitch plans.

\section{References}

[1] Mailah, M. \& Priyandoko, G. "Simulation of suspension system with adaptive fuzzy active control", International Journal simulation modeling, 2007, 1, pp: 25-36.

[2] M. kumar and S. Vijayarangan, "Analytical and experimental studies on active suspension system of light passenger vehicle to improve ride comfort", ISSN 1392 1207. MECHANIKA. 2007. Nr. 3(65).

[3] Tetsuro Butsuen, thesis, "The design of semi-active suspensions for automotive vehicles", Massachsetts institute of technology, June 28, 1989.

[4] G. Bonin, g. Cantisani, and m. Sbrolli, "Ride quality evaluation: 8 D.O.F. vehicle model calibrations" international siiv congress, palermo (Italy), 12-14 September 2007.

[5] Yuyou Liu "Semi-active damping control for vibration isolation of base disturbances" thesis, University of Southampton, December 2004.

[6] A. M. Sharaf "Investigation of All-Wheel-Drive Off-Road Vehicle Dynamics Augmented by Visco-Lock Devices" PhD Thesis, Wolfson School of Mechanical and Manufacturing Engineering Loughborough University, November 2007.

[7] W. Schiehlen, B. Hu "Spectral simulation and shock absorber identification" International Journal of Non-Linear Mechanics 38, 2003, pp. 161-171. 
[8] The Shock Absorber Test System, 'http://www.mts.com/downloads/300188-02.pdf'

[9] K. Hudha, H. Jamaluddin, P.M. Samin and R.A. Rahman "Effects of control techniques and damper constraint on the performance of a semi-active magneto-rheological damper" Int. J. Vehicle Autonomous Systems, Vol. 3, Nos. 2/3/4, 2005, pp. 230-252.

[10] J. Y. Wong "Theory of ground vehicles" Third Edition, 2001

[11] Thomas D. Gillespie "Fundamentals of Vehicle Dynamics".

[12] J. Hyvarinen "The improvement of full vehicle semi-active suspension through kinematical model" thesis, University of Oulu, 2004. 